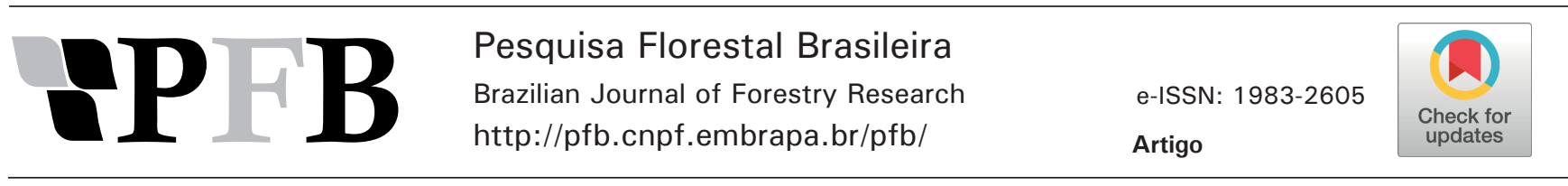

\title{
Multiplicação in vitro de Xylopia aromatica em diferentes meios de cultura e concentrações de BAP
}

\author{
Kennedy de Paiva Porfírio'(D), Miranda Titon ${ }^{1}$ (D), Ana Caroline Macedo de Castro ${ }^{1 *}$ (D), Israel Marinho Pereira ${ }^{1}$ (D), \\ Rafael Antonius Pfeilsticker de Knegt² ${ }^{2}$
}

${ }^{1}$ Universidade Federal dos Vales do Jequitinhonha e Mucuri, Campus JK, Rod. MGT 367, Km 583, n. 5000, Alto da Jacuba, CEP 39100-000, Diamantina, MG, Brasil ${ }^{2}$ Anglo American Minério de Ferro Brasil, Rod. MG 10, Km 185, Córrego Pereira, CEP 35860-000, Conceição do Mato Dentro, MG, Brasil

"Autor correspondente:
anacarolinemcastro@gmail.com

Termos para indexação:

Micropropagação

Reguladores de crescimento

Annonaceae

Index terms:

Micropropagation

Growth regulators

Annonaceae

Histórico do artigo:

Recebido em 22/01/2019

Aprovado em 22/04/2019

Publicado em 12/07/2019

doi: 10.4336/2019.pfb.39e201901895
Resumo - Este estudo teve por objetivo desenvolver uma metodologia de multiplicação in vitro para Xylopia aromatica, visando a produção de mudas, avaliando-se meios de cultura e concentrações de reguladores de crescimento mais adequados. Foram utilizados, como explantes, segmentos nodais, provindos de brotações de mudas produzidas via seminal e mantidas em viveiro. Foram testados os meios de cultura Murashige \& Skoog (MS) e Wood Plant Medium (WPM) suplementados com $800 \mathrm{mg} \mathrm{L}^{-1}$ de polivinilpirrolidona (PVP), $30 \mathrm{~g} \mathrm{~L}^{-1}$ de sacarose, $0,054 \mu \mathrm{M}$ de ácido naftalenoacético (ANA) e $6 \mathrm{~g} \mathrm{~L}^{-1}$ de ágar e concentrações de 2,22 e 3,55 $\mu \mathrm{M}$ de benzilaminopurina (BAP) para a multiplicação in vitro. Aos trinta dias, avaliou-se o número de brotações laterais emitidas e o percentual de explantes formando calos na base. As maiores taxas de multiplicação foram obtidas com o meio MS acrescido de 3,55 $\mu \mathrm{M}$ de BAP. Em relação à formação de calos na base dos explantes, o meio MS promoveu maior formação quando comparado ao WPM, no entanto não comprometeu a formação de brotos. Foi possível estabelecer as fases de introdução e multiplicação, definindo assim o meio de cultura e concentrações de reguladores de crescimento mais adequados ao cultivo in vitro de Xylopia aromatica.

\section{In vitro multiplication of Xylopia aromatica under different culture media and BAP concentrations}

\footnotetext{
Abstract - The purpose of this study was to develop an in vitro multiplication methodology for Xylopia aromatica, aiming the production of seedlings, evaluating culture media and concentrations of more suitable growth regulators. Nodal segments from seedlings produced from seeds and kept in a nursery were used as explants. The Murashige \& Skoog (MS) and Wood Plant Medium (WPM) culture media were tested supplemented with $800 \mathrm{mg} \mathrm{L}^{-1}$ of polyvinylpyrrolidone (PVP), $30 \mathrm{~g} \mathrm{~L}^{-1}$ of sucrose, $0.054 \mu \mathrm{M}$ of naphthaleneacetic acid (NAA), $6 \mathrm{~g} \mathrm{~L}^{-1}$ of agar and concentrations of 2.22 and $3.55 \mu \mathrm{M}$ of benzylaminopurine (BAP) for in vitro multiplication. At 30 days, the number of lateral sprouts emitted and percentage of explants forming callus at the base were evaluated. The highest multiplication rates were obtained on MS medium supplemented with $3.55 \mu \mathrm{M}$ of BAP. Regarding callus formation, the MS medium promoted greater formation than WPM medium, however it did not compromise the formation of shoots. It was possible to establish the introduction and multiplication phases, thus defining the culture medium and concentrations of growth regulators most suitable for in vitro culture of Xylopia aromatica.
} 


\section{Introdução}

Xylopia aromatica (Lam.) Mart., conhecida popularmente como pimenta-de-macaco, é uma espécie arbórea semidecídua, heliófita, pioneira, seletiva xerófita e zoocórica, pertencente à família Annonaceae (Lopes et al., 2011; Lorenzi, 2014), sendo recomendada para fins de recuperação de áreas degradadas situadas em locais com solos pobres e com déficit hídrico (Socolowski et al., 2012). No entanto, de acordo com esses mesmos autores, devido à dormência morfológica apresentada pelas sementes da espécie, a taxa de germinação é baixa, o que dificulta a produção em viveiro.

As aplicações da micropropagação para espécies nativas destinam-se, principalmente, para genótipos considerados de difícil multiplicação por métodos convencionais de propagação (Pinhal et al., 2011), conservação de germoplasma in vitro de espécies em extinção (Malosso et al., 2012) e para o desenvolvimento de técnicas da biologia molecular (Xavier et al., 2013). Visto que $X$. aromatica apresenta limitações em sua propagação seminal, a micropropagação é uma alternativa para tentar superar esse entrave.

Os meios nutritivos são utilizados amplamente na cultura de células, órgãos e tecidos vegetais, atuando como fonte de nutrientes e substâncias essenciais para o crescimento e desenvolvimento de plantas (Grattapaglia \& Machado, 1998). O meio de cultura MS (Murashige \& Skoog, 1962) é um dos mais utilizados para a propagação de espécies nativas, demonstrando bons resultados para diversas espécies (Oliveira et al., 2013). Em contrapartida, o meio Wood Plant Medium (WPM) (Lloyd \& McCown, 1981) foi desenvolvido especialmente para o cultivo in vitro de espécies lenhosas, sendo muito utilizado para espécies florestais (Oliveira et al., 2013).

Uma das principais dificuldades da micropropagação de espécies lenhosas baseia-se em estabelecer combinações entre elementos do meio de cultura que proporcionem o crescimento e desenvolvimento adequados dos explantes (Oliveira et al., 2013). Cada fase da micropropagação necessita de um controle na proporção dos reguladores de crescimento, sendo utilizado com maior frequência um balanço entre auxina e citocinina (Xavier et al., 2013).

Considerando a importância da $X$. aromatica, a dificuldade em propagar a espécie por métodos convencionais e a carência de estudos relacionados à sua micropropagação, esta pesquisa teve como objetivo desenvolver uma metodologia de multiplicação in vitro, visando a produção de mudas, avaliando-se as condições de cultivo in vitro para definição de meio de cultura de cultura e concentrações de reguladores de crescimento mais adequados.

\section{Material e métodos}

Os experimentos foram realizados no Laboratório de Melhoramento Florestal, da Universidade Federal dos Vales do Jequitinhonha e Mucuri, em Diamantina, MG.

Foram utilizados explantes de segmentos nodais, contendo gemas axilares, oriundos de brotações de plantas de Xylopia aromatica produzidas via seminal e mantidas em casa de vegetação, com irrigação somente no substrato até a emissão de novas brotações.

Para introdução in vitro, fez-se a desinfestação das brotações coletadas em solução fungicida durante $15 \mathrm{~min}$, sendo lavadas seis vezes em água destilada e autoclavada. Após esse procedimento, os segmentos nodais de aproximadamente $2 \mathrm{~cm}$ foram excisados e imersos em álcool $70 \%$ durante $30 \mathrm{~s}$. Imediatamente após, esses foram imersos por $5 \mathrm{~min}$ em solução de hipoclorito de sódio $2 \%$, adicionada de 5 gotas de Tween 20 para cada $100 \mathrm{~mL}$ de solução. Os explantes foram então lavados seis vezes em água destilada e autoclavada e inoculados em tubos de ensaio contendo meio de cultura.

Para o estabelecimento in vitro utilizou-se o meio Murashige \& Skoog (MS), com 50\% dos sais e vitaminas; $30 \mathrm{~g} \mathrm{~L}^{-1}$ de sacarose; $800 \mathrm{mg} \mathrm{L}^{-1}$ de polivinilpirrolidona (PVP); 2,22 $\mu \mathrm{M}$ de benzilaminopurina (BAP); 0,54 $\mu \mathrm{M}$ de ácido naftalenoacético (ANA); e $6 \mathrm{~g} \mathrm{~L}^{-1}$ de ágar. $\mathrm{O}$ experimento foi instalado com gemas emitidas e isentas de contaminação.

Uma exsicata da espécie está depositada no Herbário Dendrológico Jeanine Felfili (HDJF), situado no Departamento de Engenharia Florestal da Universidade Federal dos Vales do Jequitinhonha e Mucuri, sob o número de registro $\mathrm{HDJF}$ - 3359.

\section{Meios de cultura e bioensaios}

Utilizou-se os meios de cultura MS e Wood Plant Medium (WPM), suplementados com $800 \mathrm{mg} \mathrm{L}^{-1}$ de PVP, $30 \mathrm{~g} \mathrm{~L}^{-1}$ de sacarose e $6 \mathrm{~g} \mathrm{~L}^{-1}$ de ágar. Foram utilizadas as concentrações de 2,22 e 3,55 $\mu \mathrm{M}$ de BAP e $0,054 \mu \mathrm{M}$ de ANA. 
O meio de cultura teve o $\mathrm{pH}$ ajustado para $5,8 \pm$ 0,02 , antes da inclusão do ágar. Foi autoclavado por $15 \mathrm{~min}$ à $121^{\circ} \mathrm{C}$ e pressão de $1 \mathrm{~atm}$, sendo resfriado antes da inoculação do material vegetal.

Ainoculação foi feita em tubos de ensaiode $25 \times 150 \mathrm{~mm}$, vedados com tampas plásticas, contendo $10 \mathrm{~mL}$ de meio de cultura. Após, os explantes foram transferidos para a sala de cultura $25 \pm 2{ }^{\circ} \mathrm{C}$, fotoperíodo de $16 \mathrm{~h}$ e intensidade luminosa de $40 \mu \mathrm{mol} \mathrm{m} \mathrm{m}^{-2}$.

Adotou-se o delineamento experimental inteiramente casualizado, com quatro tratamentos (MS + 2,22 BAP; $\mathrm{MS}+3,55 \mathrm{BAP} ; \mathrm{WPM}+2,22 \mathrm{BAP}$ e WPM $+3,55 \mu \mathrm{M}$ de BAP), com quatro repetições e seis tubos com um explante por repetição. Este experimento foi constituído pelo cultivo inicial e dois cultivos subsequentes (cultivo inicial, subcultivos 1 e 2). Durante os subcultivos, respeitou-se o histórico do explante, ou seja, a repicagem de cada explante foi realizada para o tratamento semelhante ao do seu cultivo anterior. Os dados foram submetidos à análise de variância e as médias comparadas pelo teste de Tukey a 5\% de significância.

Aos 30 dias de cada subcultivo, fez-se a avaliação do número médio de brotações laterais emitidas por explante em cada tratamento. Para a avaliação do percentual de explantes com formação de calos, foram consideradas quatro categorias de calos (ausente, baixo, médio e alto). Essas categorias foram definidas por meio de uma escala visual de avaliação em relação à área de ocupação do calo dentro do tubo de ensaio ( $0 \%$ : ausente; 25\%: baixo; $50 \%$ : médio; $75-100 \%$ : alto). Após, avaliouse o percentual de explantes em cada categoria.

\section{Resultados}

Foram encontradas diferenças entre os tratamentos em todos os subcultivos de Xylopia aromatica, em relação ao número de brotações emitidas.

No cultivo inicial e nos subcultivos subsequentes, o meio Murashige \& Skoog (MS) apresentou melhor desempenho para emissão de brotações, quando comparado com o meio Wood Plant Medium (WPM) (Figura 1). As respostas de emissão de brotações em explantes cultivados em meio MS acrescido de benzilaminopurina (BAP) foram consideradas satisfatórias, pois possibilitaram o incremento em altura e em número de brotações, originando novos explantes durante a fase de multiplicação (Figura 2).

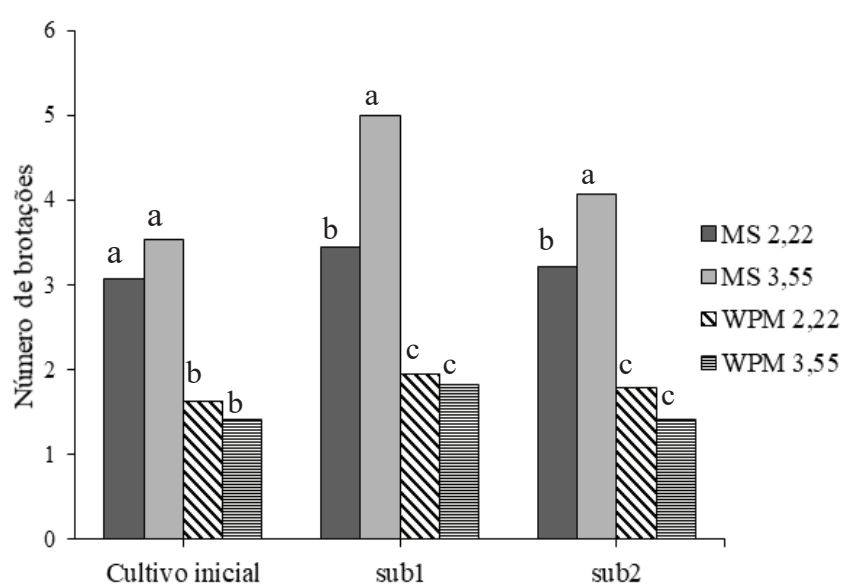

Figura 1. Número médio de brotações emitidas por explante, em resposta aos meios de cultura e concentrações de BAP, no cultivo inicial e nos subcultivos 1 e 2 (sub1 e sub2). Médias seguidas pela mesma letra não diferem entre si pelo teste de Tukey, a 5\% de significância, dentro de um mesmo subcultivo.

Figure 1. Average number of sprouts emitted per explants, in response to culture media and BAP concentrations in the initial culture and subcultures 1 and 2 (sub1 and sub2). Means followed by the same letter do not differ within the same subculture by Tukey's test at $5 \%$ of significance.

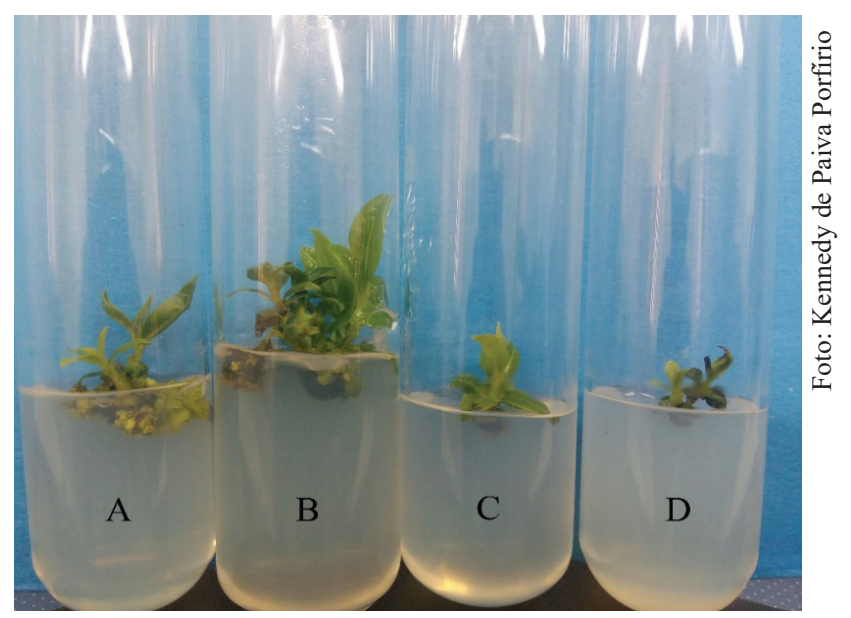

Figura 2. Efeito da concentração de BAP na multiplicação de explantes de Xylopia aromatica após 30 dias em meio de cultura contendo $0,054 \mu \mathrm{M}$ de ANA. A) $\mathrm{MS}+2,22 \mathrm{BAP}, \mathrm{B})$ $\mathrm{MS}+3,55 \mathrm{BAP}, \mathrm{C}) \mathrm{WPM}+2,22 \mathrm{BAP}$ e D) $\mathrm{WPM}+3,55 \mathrm{BAP}$.

Figure 2. Effect of BAP concentration on the multiplication of Xylopia aromatica explants after 30 days in culture medium containing $0.054 \mu \mathrm{M}$ of ANA. A) $\mathrm{MS}+2.22 \mathrm{BAP}, \mathrm{B}) \mathrm{MS}+$ 3.55 BAP, C) $\mathrm{WPM}+2.22 \mathrm{BAP}$ and $\mathrm{D}) \mathrm{WPM}+3.55 \mathrm{BAP}$. 
Não foi verificado efeito fitotóxico do BAP e também não foi observada oxidação dos explantes durante a fase de multiplicação.

Observou-se que o número de brotações emitidas, em todos os tratamentos, tendeu a aumentar do cultivo inicial para o subcultivo 1 , seguido de decréscimo do subcultivo 1 para o 2 (Figura 2).

No cultivo inicial, os tratamentos MS + 2,22 BAP e MS + 3,55 BAP foram semelhantes, diferindo apenas dos tratamentos WPM + 2,22 BAP e WPM + 3,55 BAP. Entretanto, nos demais subcultivos, o tratamento MS + 3,55 BAP mostrou-se superior em relação aos demais.

Em geral, no meio MS os explantes apresentaram folhas verdes, vigorosas e brilhantes durante toda fase experimental (Figuras 3A e 3B). No entanto, no meio WPM, no subcultivo 2, os explantes perderam o vigor, apresentando folhas com coloração amarelada e redução do tamanho (Figuras 3C e 3D).

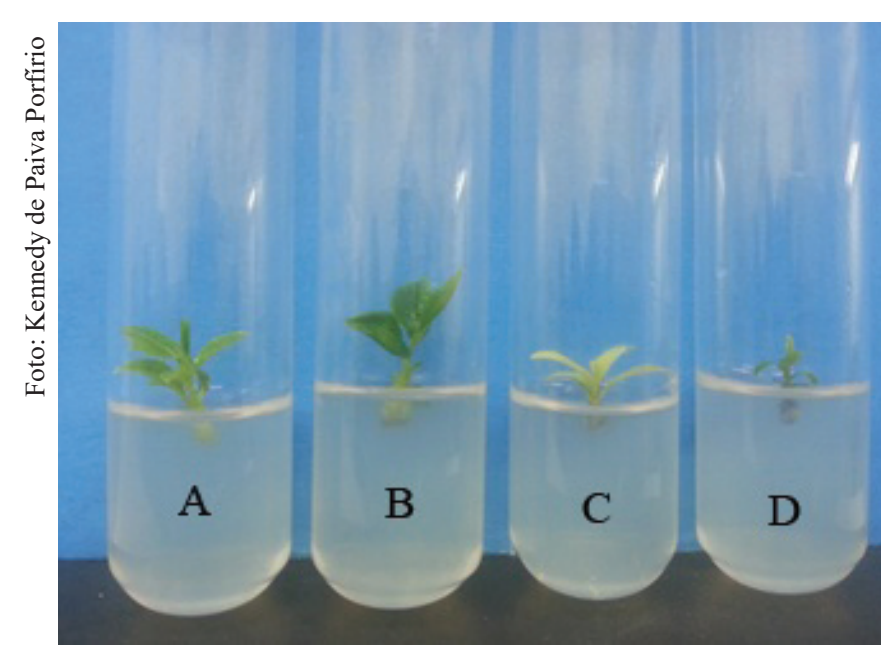

Figura 3. Multiplicação de explantes de Xylopia aromatica no subcultivo 2. A) $\mathrm{MS}+2,22 \mathrm{BAP}, \mathrm{B}) \mathrm{MS}+3,55 \mathrm{BAP}, \mathrm{C}$ ) $\mathrm{WPM}+2,22 \mathrm{BAP}$ e D) $\mathrm{WPM}+3,55 \mathrm{BAP}$.

Figure 3. Multiplication of Xylopia aromatica explants in subculture 2. A) $\mathrm{MS}+2.22 \mathrm{BAP}, \mathrm{B}) \mathrm{MS}+3.55 \mathrm{BAP}, \mathrm{C}) \mathrm{WPM}$ $+2.22 \mathrm{BAP}$ and $\mathrm{D}) \mathrm{WPM}+3.55 \mathrm{BAP}$.

Com relação à formação de calos, avaliada por meio da área de ocupação do calo em relação ao meio de cultura (Figura 4D), foi observado $71 \%$ de explantes sem calos (Figura 4A) no cultivo inicial, 13\% com baixo percentual e $8 \%$ com médio e alto percentual para o tratamento $\mathrm{MS}+2,22 \mathrm{BAP}$. O tratamento $\mathrm{MS}+3,55 \mathrm{BAP}$ apresentou $63 \%$ de explantes sem calos, $33 \%$ com baixo percentual e $4 \%$ com percentual médio. Nos demais tratamentos, o percentual observado foi baixo e ausente. No subcultivo 1 (Figura 4B), houve queda no percentual de calos na categoria alto no tratamento MS + 2,22 BAP, sendo que as categorias médio e baixo apresentaram $50 \%$ cada. No tratamento MS $+3,55$, houve aumento no percentual de calos nas categorias médio e alto $(8 \%$ e $58 \%$, respectivamente) e no tratamento $\mathrm{WPM}+2,22$ houve queda na classe baixo, passando de $29 \%$ para $21 \%$. Neste caso a maior quantidade de explantes não apresentava calos (79\%). Em geral, observou-se ausência de calos ou baixo calejamento no subcultivo 2 (Figura $4 \mathrm{C})$.

A porcentagem de calos foi superior nos tratamentos que continham o meio MS, quando comparado com o meio WPM, porém, a quantidade de calos foi diminuindo gradativamente após cada subcultivo. Ainda assim, a formação de calos não comprometeu a formação de brotos.
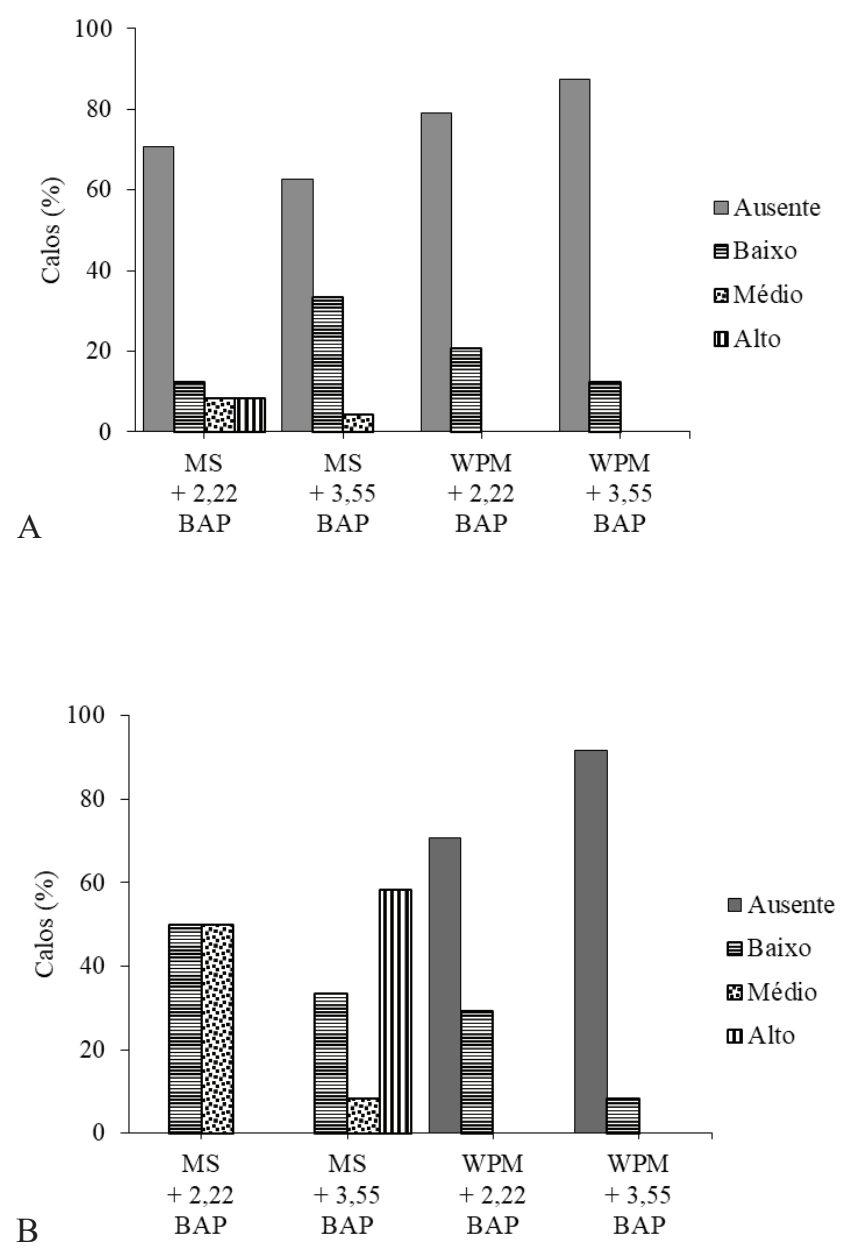

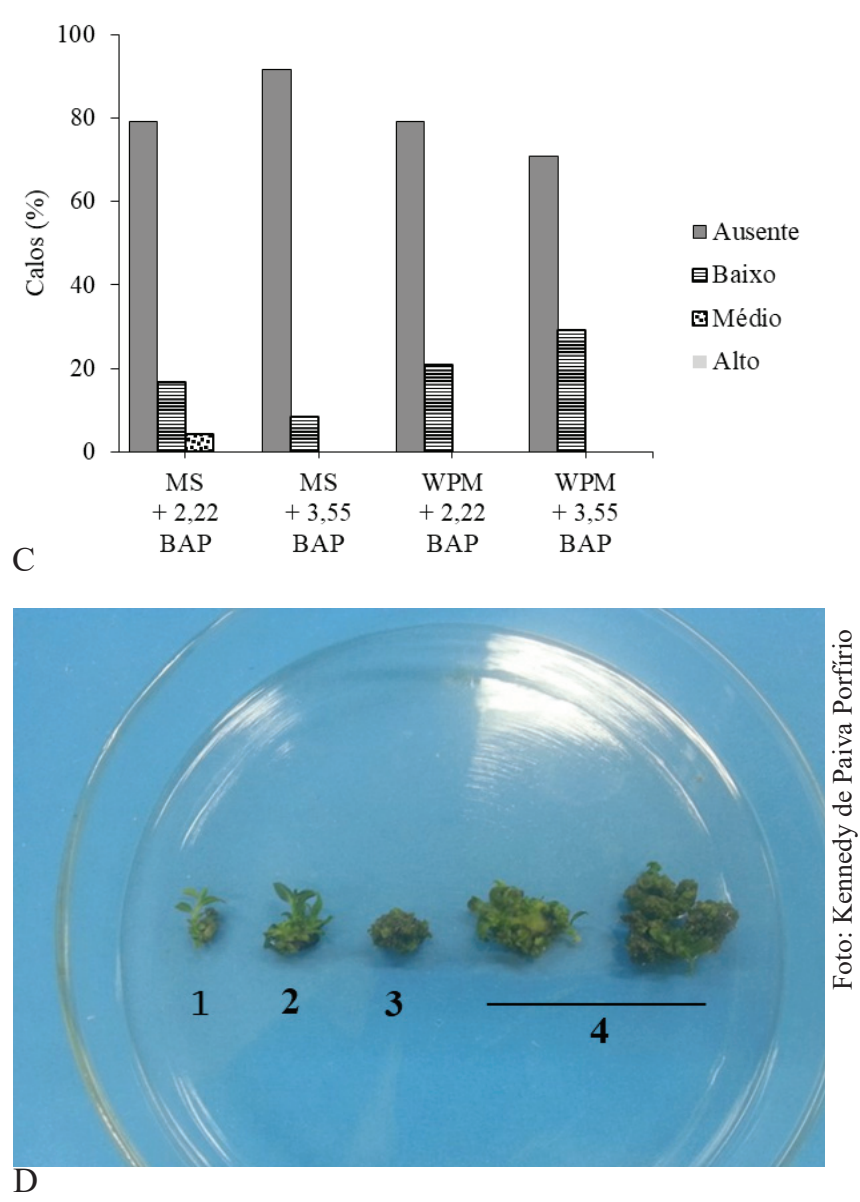

Figura 4. Percentual de explantes de Xylopia aromatica com calos nas quatro categorias, em resposta aos meios de cultura e concentrações de BAP no cultivo inicial (a), subcultivo 1 (b), subcultivo 2 (c) e escala visual das categorias de calos (d): 1) ausente, 2) baixo, 3) médio e 4) alto.

Figure 4. Percentage of Xylopia aromatica explants with callus in the four categories in response to culture media and BAP concentrations in the initial culture (a), subculture 1 (b), subculture 2 (c) and visual scale of callus categories (d): 1) absent, 2) low, 3) medium and 4) high.

\section{Discussão}

Trabalhos que abordem a micropropagação do gênero Xylopia não são reportados na literatura. No entanto, para a família Annonaceae, principalmente para o gênero Annona, a possibilidade de uso da micropropagação tem sido investigada com o intuito de contornar problemas em relação à propagação por métodos convencionais (Encina et al., 2014).

O destaque do meio Murashige \& Skoog (MS), em relação aos demais meios de cultura, muitas vezes é elucidado pela concentração mais elevada de nitrogênio presente nesse meio em relação aos demais (Rodrigues et al., 2012).

Não existe uma formulação padrão de meio de cultura, sendo utilizadas diversas formulações no cultivo in vitro. Contudo, o meio MS, com suas modificações e diluições, tem apresentado maior sucesso para propagação de diversas espécies lenhosas (Golle et al., 2012).

Este fato foi constatado por Brondani et al. (2010), que verificaram para Liquidambar styraciflua que o meio de cultura MS apresentou efeito superior para massa fresca da brotação e comprimento das brotações emitidas por explante, quando comparado com o meio Wood Plant Medium (WPM). No presente estudo, os resultados obtidos indicaram que o meio WPM não é o melhor para o cultivo in vitro de Xylopia aromatica. Resultados superiores do meio MS também foram observados por Miranda et al. (2016), quando testaram os meios MS $50 \%$, MS 100\%, WPM 50\% e WPM 100\%, com adição de $0,6 \mathrm{mg} \mathrm{L}^{-1}$ benzilaminopurina (BAP) e $0,01 \mathrm{mg} \mathrm{L}^{-1} \mathrm{de}$ ácido naftalenoacético (ANA). Os autores verificaram que o meio MS 100\% promoveu o maior número de brotações em explantes de Eremanthus incanus.

Diferentemente dos resultados obtidos neste trabalho, Freitas et al. (2016) verificaram que o uso de $1 \mu \mathrm{M}$ de BAP em meio WPM proporcionou maior número de gemas e folhas, sendo recomendado para a multiplicação in vitro de Annona emarginata.

Entre os fatores que controlam a morfogênese in vitro de anonáceas, podem-se destacar os reguladores de crescimento, especialmente o balanço entre auxina e citocinina. O BAP tem sido a citocinina mais utilizada para induzir brotações em diversas espécies de anonáceas (Nagori \& Purohit, 2004). Em diversos estudos de multiplicação de espécies lenhosas, a quantidade de brotos aumentou à medida que se elevaram as concentrações de BAP (Kielse et al., 2009). Os reguladores de crescimento ANA e BAP demonstraram importância na propagação in vitro de Dioscorea rotundata, uma vez que combinações de ambos favoreceram o desempenho da espécie (Ezeibekwe et al., 2009).

As citocininas estimulam a formação e o crescimento da parte aérea até uma determinada concentração, que varia de acordo com as exigências de cada espécie. Acima de determinada concentração, as citocininas podem apresentar efeito fitotóxico no desenvolvimento morfogênico dos explantes (Grattapaglia \& Machado, 
1998). O fato de não ter sido verificado efeito fitotóxico do BAP no presente estudo, deve-se à, provavelmente, as concentrações utilizadas estarem dentro da zona de máximo incremento para o desenvolvimento dos explantes de Xylopia aromatica. Deccetti et al. (2005), ao compararem diversas concentrações de BAP, usado isolado ou em combinação com concentrações de ANA, e com ou sem 1,0 $\mathrm{mg} \mathrm{L}^{-1}$ de $\mathrm{GA}_{3}$ em meio básico MS para a multiplicação de Annona glabra, verificaram que todos os tratamentos, mesmo aqueles sem reguladores de crescimento, obtiveram, em média, 1,5 brotos por segmento nodal. Entretanto, os brotos mais desenvolvidos foram obtidos com $0,5 \mathrm{mg} \mathrm{L}^{-1}(2,22 \mu \mathrm{M})$ de BAP utilizado isoladamente.

Nagori \& Purohit (2004) demonstraram que a adição de citocininas no meio de cultura é essencial para indução de brotos adventícios, em segmentos de hipocótilos de Annona squamosa, e que um maior número de brotações poderia ser obtido com a utilização de BAP em concentrações de 5,0 $\mathrm{mg} \mathrm{L}^{-1}$, quando comparado com as demais concentrações de BAP e com concentrações de Kinetin e Thidiazuron (TDZ).

Os reguladores de crescimento são de grande importância para o meio de cultura, dada sua atuação no crescimento e no controle, em grande parte, do padrão de desenvolvimento in vitro dos explantes. Sua utilização e teores variam em função dos objetivos, da espécie e do tipo de explante (Xavier et al., 2013). A interação entre baixas concentrações de auxinas e concentrações mais elevadas de citocininas pode favorecer a indução de brotações, por estimular as divisões celulares. A presença de auxina em concentrações elevadas pode estimular a indução de calo (Cheng et al., 2013).

Concentrações mais altas de citocinina podem promover a formação de calos, o que não é objetivo na fase de multiplicação. A formação de calos na base do explante pode comprometer a proliferação de gemas axilares e a funcionalidade do sistema radicular, pois podem inibir a protusão de raízes. Consequentemente, interferem no completo desenvolvimento in vitro e na aclimatização das plântulas (Grattapaglia \& Machado, 1998). A fase de calo, por se tratar de uma forma indireta de organogênese, em períodos prolongados de cultivo in vitro, também pode ocasionar a variação somaclonal (George \& Sherrington, 1984).

\section{Conclusões}

O meio MS acrescido de 3,55 $\mu \mathrm{M}$ de benzilaminopurina (BAP) foi mais adequado na fase de multiplicação de Xylopia aromatica, quando comparado com o meio Wood Plant Medium (WPM).

Foi possível estabelecer as fases de introdução e multiplicação de gemas axilares, definindo assim o meio de cultura e concentrações de reguladores de crescimento mais adequados ao cultivo in vitro de Xylopia aromatica, dando início a um protocolo de micropropagação da espécie.

\section{Agradecimentos}

O presente trabalho foi realizado com apoio da Coordenação de Aperfeiçoamento de Pessoal de Nível Superior - Brasil (CAPES) - Código de Financiamento 001; à Universidade Federal dos Vales do Jequitinhonha e Mucuri (UFVJM), pela formação profissional e apoio financeiro e à Anglo American Minério de Ferro Brasil, pelo apoio logístico e financeiro.

\section{Referências}

Brondani, G. E. et al. Desinfestação e meio de cultura para o Estabelecimento in vitro de segmentos nodais de Liquidambar styraciflua. Floresta, v. 40, n. 3, p. 541-554, 2010. http://dx.doi. org/10.5380/rf.v40i3.18916.

Cheng, Z. J. et al. Pattern of auxin and cytokinin responses for shoot meristem induction results from the regulation of cytokinin biosynthesis by AUXIN RESPONSE FACTOR3. Plant Physiology, v. 161, n. 1, p. 240-251, 2013. http://dx.doi.org/10.1104/ pp.112.203166.

Deccetti, S. F. C. et al. La micropropagation d'Annona glabra L. à partir de segments nodaux. Fruits, v. 60, n. 5, p. 319-325, 2005.

Encina, C. L. et al. Biotechnology applied to Annona species: a review. Revista Brasileira de Fruticultura, v. 36, n. spe1, p. 1721, 2014. http://dx.doi.org/10.1590/S0100-29452014000500002.

Ezeibekwe, I. O. et al. Effects of combination of diferente levels of Auxin (NAA) and Cytokinin (BAP) on in vitro propagation of Dioscorea rotundata L. (White Yam). New York Science Journal, v. 2, n. 5, p. 1-8, 2009. http://dx.doi.org/jmolgene.2009.18.22.

Freitas, R. T. et al. In vitro culture of Annona emarginata: a rootstock for commercial annonaceae species. Plant Cell Culture \& Micropropagation, v. 12, n. 1, p. 1-6, 2016.

George, E. F. \& Sherrington, P. D. (Ed.). Plant propagation by tissue culture. Eversley: Exegetics, 1984. 709 p. 
Golle, D. P. et al. Estabelecimento e desenvolvimento in vitro de Eugenia involucrata DC.: influência do tipo de explante e do meio nutritivo. Ciência Florestal, v. 22, n. 1, p. 207-214, 2012. DOI: $10.5902 / 198050985092$.

Grattapaglia, D. \& Machado, M. A. Micropropagação. In: Torres, A. C. et al. Cultura de tecidos e transformação genética de plantas. Brasília, DF: EMBRAPA-SPI: EMBRAPA-CNPH, 1998. p. 183-260.

Kielse, P. et al. Regeneração in vitro de Parapiptadenia rigida. Ciência Rural, v. 39, n. 4, p. 1088-1094, 2009. DOI: 10.1590/ S0103-84782009005000046.

Lloyd, G. \& Mccown, B. Commercially feasible micropropagation of mountain laurel, (Kalmia latifolia), by use of shoot tip culture. Combined Proceedings: International Plant Propagator's Society, n. 30 , p. $421-427,1981$.

Lopes, S. F. et al. Caracterização ecológica e distribuição diamétrica da vegetação arbórea em um remanescente de floresta estacional semidecidual na Fazenda Experimental do Glória, Uberlândia, MG. Bioscience Journal, v. 27, p. 322-335, 2011.

Lorenzi, H. (Ed). Árvores brasileiras: manual de identificação e cultivo de plantas arbóreas nativas do Brasil. Nova Odessa, SP: Editora Plantarum, 2014. 388 p.

Malosso, M. G. et al. Micropropagation and in vitro conservation of Jacaranda decurrens Cham. Journal of Medicinal Plants Research, v. 6, n. 7, p. 1147-1154, 2012. http://dx.doi.org/10.5897/JMPR11.436.

Miranda, N. A. et al. Meio de cultura, reguladores de crescimento e formas de vedação de tubos de ensaio na multiplicação in vitro de candeia (Eremanthus incanus (Less.) Less). Scientia Forestalis, v. 44, n. 112, p. 1009-1018, 2016. http://dx.doi.org/10.18671/scifor. v44n112.22.

Murashige, T. \& Skoog, F. A revised medium for rapid growth and bioassays with tobacco tissue cultures. Physiologia Plantarum, v. 15, p. 473-497, 1962. http://dx.doi.org/10.1111/j.1399-3054.1962. tb08052.x.

Nagori, R. \& Purohi, S. D. In vitro plantet regeneration in Annona squamosa thought direct shoot but differentiation on hypocotyl segmen ts. Scientia Horticulturae, v. 99, p. 89-98, 2004. http:// dx.doi.org/10.1016/S0304-4238 (03)00084-0.

Oliveira, L. S. et al. Micropropagação de espécies florestais brasileiras. Pesquisa Florestal Brasileira, v. 33, n. 76, p. 439-453, 2013. http://dx.doi.org/10.4336/2013.pfb.33.76.481.

Pinhal, H. F. et al. Aplicações da cultura de tecidos vegetais em fruteiras do Cerrado. Ciência Rural, v. 41, n. 7, p. 1136-1142, 2011. http://dx.doi.org/10.1590/S0103-84782011005000089.

Rodrigues, M. R. et al. Effects of flask sealing and growth regulators on in vitro propagation of neem (Azadirachta indica A. Juss.). In vitro Cellular \& Developmental Biology: Plant, v. 48, n. 1, p. $67-$ 72, 2012. http://dx.doi.org/10.1007/s11627-011-9398-8.

Socolowski, F. et al. Viability of recently harvested and stored Xylopia aromatica (Lam.) Mart. (Annonaceae) seeds. Revista Brasileira de Sementes, v. 34, n. 3, p. 408-415, 2012. http://dx.doi.org/10.1590/ S0101-31222012000300007.

Xavier, A. et al. (Ed.). Silvicultura clonal: princípios e técnicas. Viçosa, MG: Ed. da UFV, 2013. 279 p. 